\title{
ROBERTO JUARROZ: LOS PORTALONES DEL SUEÑO
}

\author{
POR \\ JULIAN PALLEY \\ University of California, Irvine
}

El poeta argentino Roberto Juarroz ha captado, con más acierto que cualquier poeta que conozco, la naturaleza paradójica de la existencia humana: la vida como contingencia, siempre en el borde, en el punto de caer o ascender. Un crítico ${ }^{1}$ ha dicho que la caída es característica de su poesía, como destilación del anéantissement simbolista. Quizá haya mejor manera de acercarse al movimiento heraclitiano de sus versos.

Más que de la caída, podemos hablar de un movimiento continuo en todos los sentidos y de la interpenetración de los estados espaciales, temporales y oníricos del ser humano: arriba-abajo, detrás-adelante, dentro-fuera, pasadopresente-futuro, sueño-vigilia, ser-no ser, abierto-cerrado y el deslizamiento derrideano del significado bajo el significante. O sea, un fluir sin fin entre estados de la conciencia, un voltearse espiral de X a Z y vuelto a X; o el río de Heráclito como es percibido por nuestra conciencia, la cual también está en estado de flujo incesante.

\author{
La rueda gira y gira \\ los caminos se enrollan \\ alrededor de la rueda \\ y la rueda se los lleva... \\ IX, $12^{2}$
}

\footnotetext{
1 Francisco Rivera, "Roberto Juarroz o el descenso a las profundidades", Cuadernos hispanoamericanos 420. Junio, 1985, 91-116. Véase también Thorpe Running, "La poética explosiva de Roberto Juarroz", Revista Iberoamericana 49, 125. Oct.-Dic. 1983, 853-866.

${ }^{2}$ Poesía vertical de Juarroz ha aparecido en once ediciones sucesivas. Las que he podido consultar son: Poesía vertical, Caracas: Monte Avila Editores, 1976 (incluye la primera, 1958, la segunda, 1963, la cuarta, 1969, la quinta, 1974, y la sexta, 1975); Octava. Buenos Aires: Carlos Lohlé, 1984; Novena y Décima. Buenos Aires, 1986; Undécima. Valencia: Pretextos, 1988. Los poemas de cada volumen no llevan título sino números; así que me refiero a ellos por tomo y número, por. ej., $\mathrm{X}, 10$.
} 
En esta poesía, que ha sido caracterizada como mística y metafísica, pero cuya descripción más adecuada podria ser fenomenológica, la vida es comparada a un texto, un palimpsesto re-escrito continuamente:

Somos el borrador de un texto que nunca será pasado en limpio ... $\mathrm{IX}, 50$

Pero los poemas numerosos sobre el sueño-la vigilia quizá más adecuadamente ejemplifiquen esta interpenetración de modos y estados de la conciencia. El muro que separa el sueño de la vigilia (los portalones del título de este ensayo), y el estado hipnagógico de Freud; esa piel porosa que divide la conciencia del inconsciente, como la línea que divide el significado del significante, constituyen la metáfora que emerge de esta exploración lírica extraordinaria de la psique:

Los muros del sueño se recuestan a veces en el pecho ...

$\mathrm{XI}, 48$

O este comentario sobre el sueño lúcido que llega a los límites extremos de la paradoja:

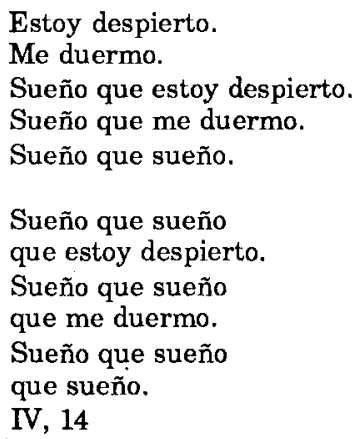

El sueñoy el inconsciente como las fuentes del arte, la lenta elaboración que intenta resolver los problemas, las doradas abejas de Antonio Machado ${ }^{3}$, son enunciados o sugeridos en varios poemas notables. Poemas o fragmentos de poemas se le han aparecido al hablante en los sueños:

\footnotetext{
${ }^{3}$ Véase "The Secret Galleries of Antonio Machado", en mi libro The Ambiguous Mirror: Dreams in Spanish Literature . Valencia: Hispanófila-Albatros, 1983.
} 


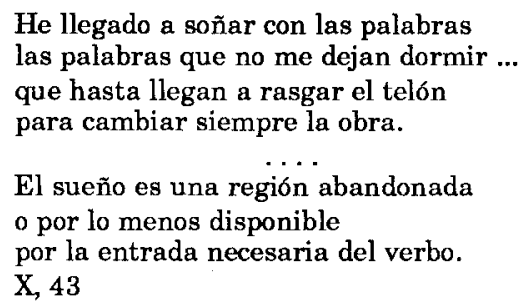

Y en otro contexto:

Toda palabra debe ser soñada antes de llegar al poema.

$\mathrm{X}, 12$

A veces el camino del sueño a la palabra escrita se ve como un círculo, un ourobouros, en que las "figuras" entran al poema para luego volver al inconsciente; pero algún indicio de la palabra soñada permanece:

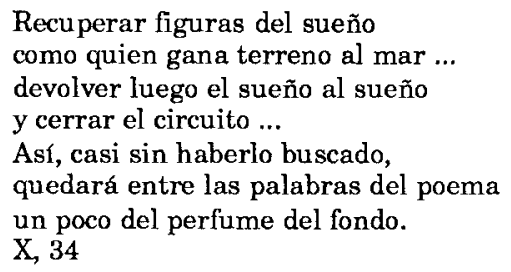

$\mathrm{Y}$ en $\mathrm{X}, 15$, el trabajo del sueño se describe como un continuo, una "narración," casi el inconsciente colectivo junguiano, en que el trabajo onírico produce figuras, mitos, narrativa. Casi todos los poemas que tratan del sueño como fuente del arte se encuentran en la Décima poesía vertical, pero en VIII, 65 , el inconsciente es un laberinto fecundo que renueva la imaginación y la existencia:

En el reino cifrado de la noche, allí donde están paradas las tinieblas ...

La conversión teje su trama insólita, su indómito laberinto de inusuales diseños y en medio de la noche se abre un paso en el tiempo, como un desfiladero de infinitos ...

La región ambigua entre el sueño y la vigilia, el estado hipnagógico, se vislumbra en varios poemas, empezando con la Sexta poesía vertical. En el 
poema 64 el hablante se encuentra con un "pedazo del sueño" y un "pedazo de vigilia":

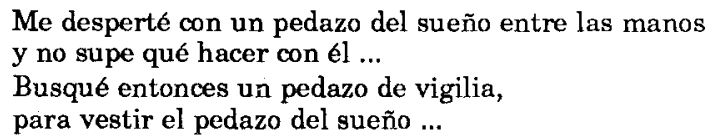

El hablante no puede cruzar la barrera entre el sueño y la vigilia. Metafóricamente, sólo puede estar en una región u otra, con uno u otro de los "pedazos" en su mano. Por otra parte, en VIII, 73, es incapaz de separar los dos estados:

Se han unido el sueño y la vigilia y no puedo ni quiero separarlos.

Aquí la juntura de sueño-vigilia es la fuente del "río", quizás una figura por la creación poética:

Tal vez en este ayuntamiento pueda inspirarse lo demás que debiera estar junto, lo demás que separa el gran río...

En el siguiente poema la separación porosa entre el sueño y la vigilia se ve como un insecto de cuerpo elástico en transformación constante:

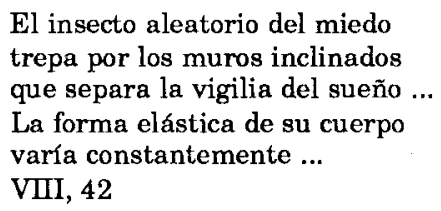

En IX, 34, paradójicamente, el hablante emplea el estado hipnagógico como la metáfora adecuada por nuestra existencia despierta, diurna. Aunque parece que estamos despiertos, el estado onírico continuamente invade nuestra condición diurnal.

Despertar es siempre una difícil emergencia: reencender la lucidez como quien recomienza el mundo.

Por eso nos quedamos en los estados intermedios. 
El hombre no es una criatura despierta:

desconoce lo abierto ...

Experimentos recientes en la fisiología del sueño identifican el "REM" (Rapid Eye Movement) como el período en que la mente sueña cuando uno está dormido. Al despertar súbitamente a un durmiente, éste generalmente puede recordar vívidamente su sueño, incluso aquellos que "nunca recuerdan sus sueños". El hablante del siguiente poema identifica un fenómeno parecido como una "experiencia-límite", una visión de las profundidades que normalmente nos está vedada:

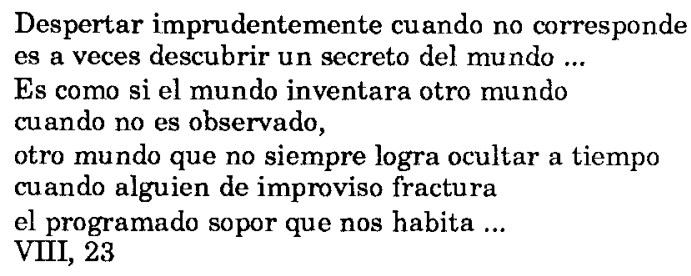

Este deslizamiento entre lo conocido y lo desconocido, entre lo finito y lo infinito (Véase IX, 14, "También el infinito/tiene un derecho y un envés") es la cualidad esencial, la esencia, que subyace por debajo de toda la poesía de Juarroz. El sueñolúcido, el sueño-dentro-del-sueño, es el foco temático de varioss de los poemas.

Pienso dentro del sueño, amo dentro del sueño.

¿Pero que ocurriria

si llegase a morir dentro del sueño?

...

En todos los ríos hay regresos, pero es difícil que una mirada se sostenga

cuando ya no existe diferencia entre el ojo abierto y el ojo cerrado.

VI, 74

¿Si estoy conciente dentro de mi sueño, - se pregunta el hablanteentonces cómo podemos distinguir el sueño de la vigilia? ¿Si muriera dentro de mi sueño, eso sería una muerte auténtica o la representación de una muerte? En tal estado se borran las diferencias. El ojo abierto y el ojo cerrado son intercambiables; quizás el ojo cerrado del sueño esté abierto a una realidad más auténtica. 
El sueño lúcido, el doble fondo de XI, 30 , sugiere que si un sueño tiene un segundo nivel, entonces quizá todos los aspectos de la existencia, incluyendo la muerte, tengan otro nivel, otro "fondo," que no es fácilmente aparente.

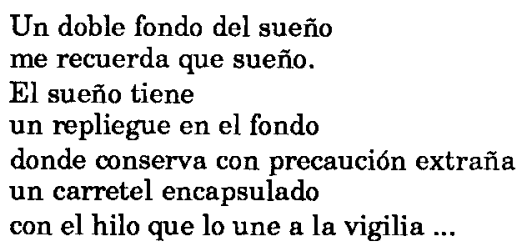

Además de la separación porosa que divide el sueño de la vigilia, hay todavía otra: entre el sueño y su cápsula, el sueño lúcido, que funciona como un hilo atado a la realidad despierta.

Otro fenómeno bien conocido de la actividad onírica es el de la palabra escrita o manuscrito borroso o ilegible mientras que el soñador trata de descifrarlo. Tal experiencia ocurre en XI (I), 10:

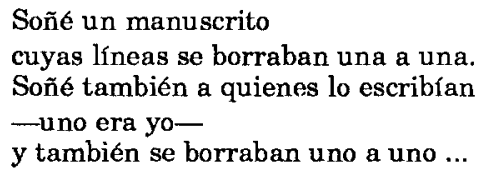

No es sólo el manuscrito el que desaparece; sus autores también, y entre ellos, el soñador. Esto alude a la calidad de palimpsesto de la escritura en general; la escritura en cuanto literatura constituye una cadena de significantes cuyo significado está en flujo: la différance. La différance luego se extiende a los autores mismos, cuya individualidad y hasta existencia están en duda. Así es que Juarroz, comenzando con un fenómeno onírico común, lo expande hasta abarcar la escritura y la literatura en general, en el contexto definido teóricamente por Jacques Derrida.

Otra meditación sobre la naturaleza transitoria de la escritura se encuentra en XI (II), 10:

Las letras se desmoronan con excesiva rapidez como velas de un culto que no ha encontrado parentesco con la noche ...

El hablante se pregunta si habrá otro modo de escritura que sea más permanente, más seguro, quizás el empleo de tintas o superficies diferentes; $o$ incluso cambiar la mano que escribe: 


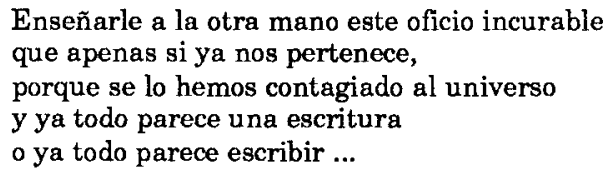

En esta vindicación de la Gramatología de aquéllos, como Unamuno, quienes han afirmado la primacía de la escritura, el hablante percibe la escritura ya no solamente como propiedad del ser humano, sino como algo que ha invadido el universo. Este supuesto, a primera vista inverosímil, adquiere credibilidad al considerar los efectos de la escritura-la razón-la ciencia sobre el planeta frágil que habitamos.

En un poema el sueño se manifiesta como un juego entre espejos infinitos, une mise en abîme:

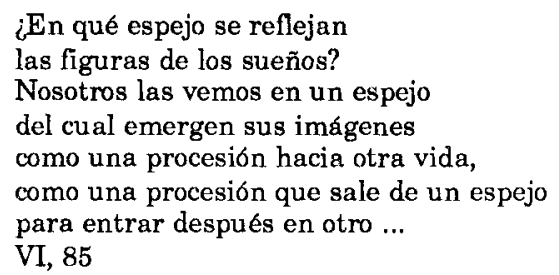

Las imágenes, despierto o dormido, se cambian infinitamente entre espejos; entre los espejos hay sólo $1 a$ mirada interceptora, la del sujeto -que también "parece un espejo". Aunque no hay nada detrás o delante de la imagen, el hablante se pregunta: “¿Por qué ilumina la luz el espectáculo?" Si la vida es un sueño, ¿por qué fuimos creados para testimoniarla?

Finalmente, uno de los poemas más llamativos sugiere que el sueño abre sus puertas a una realidad escondida en la forma de una pieza de música demasiado intensa para la memoria, cuya única condición posible es el olvido:

Abriendo los portalones del sueño, me despierta el fantasma de una música en la que ni siquiera reconozco la melodía o los instrumentos que la ejecutan ... $\mathrm{V}, 14$

Los portalones son una apertura al inconsciente y sus misterios; también representan, en forma de Jano, lo interior y lo exterior, lo que mira para adentro al inconsciente, o para afuera a la realidad despierta. Si buscásemos un sólo emblema para la poesía de Juarroz, quizá estos "portalones del sueño", que nos hablan de un movimiento doble y recíproco de conciencia-inconsciente, sirvan mejor para caracterizarla. 
